\title{
Pengembangan Aplikasi Berbasis Web untuk Pemesanan Jasa Sablon Pakaian
}

\author{
Tiffani Maria Bernadetta'), \& Arnold Aribowo ${ }^{2)}$ \\ ${ }^{1,2)}$ Program Studi Sistem Informasi, Fakultas Ilmu Komputer Universitas Pelita Harapan \\ Jl. MH Thamrin Boulevard 1100, Klp. Dua, Kec. Klp. Dua, Tangerang, Banten 15811 Telp (021) 5460901 \\ Website: https://www.uph.edu/ ,E-mail: tiffanimaria@gmail.com, arnold.aribowo@uph.edu
}

\begin{abstract}
Abstrak - Pakaian merupakan salah satu kebutuhan pokok yang harus dipenuhi oleh setiap individu. Setiap orang dapat membeli pakaian untuk memenuhi kebutuhannya masing-masing. Bisnis penjualan pakaian jadi (ready-to-wear) telah membantu konsumen dalam memenuhi kebutuhannya. Selain bisnis pakaian jadi, bisnis pakaian sablon diminati karena dapat memenuhi kebutuhan konsumen secara lebih spesifik, baik dalam hal desain, warna, ukuran, dan kuantitas. Proses pemesanan pakaian sablon pada umumnya dilakukan melalui dua cara, yaitu; customer datang langsung ke toko, dan customer melakukan pemesanan melalui WhatsApp. Pemesanan yang dilakukan dengan cara datang ke toko menjadi kurang efisien, karena customer harus meluangkan waktunya dengan datang ke toko secara langsung untuk melakukan pembelian. Pemesanan yang dilakukan melalui WhatsApp memiliki kendala untuk penjual, yaitu ketika chat dari customer yang masuk terlalu banyak sehingga menyebabkan kesulitan untuk melakukan pencatatan pesanan yang masuk. Sistem usulan dirancang menggunakan metodologi pengembangan sistem waterfall dan dikembangkan menggunakan bahasa pemrograman PHP dengan framework CodeIgniter. Pemodelan sistem pada penelitian ini menggunakan use case diagram, activity diagram, class diagram dan entity relationship diagram. Hasil akhir dari penelitian yang telah dilakukan adalah aplikasi berbasis web yang dapat digunakan untuk menunjang serta mempermudah transaksi penjualan dan pembelian pakaian sablon jadi (ready-to-wear) dan pakaian sablon custom.
\end{abstract}

Kata kunci: e-commerce, pakaian jadi, pakaian sablon, sistem informasi

\begin{abstract}
Clothing is one of the necessities that every individual needs to fulfill. Everyone can buy clothes to fulfill their needs. The ready-to-wear apparel business has helped consumers to meet their needs. In addition to apparel business, screen printing business is in demand because it can meet the needs of consumers more specifically in terms of design, color, size, and quantity. The process of ordering screen printing clothes is generally done in two ways; customers come directly to the store, and customers place orders through WhatsApp. Orders made by coming to the store become less efficient because customers must spend their time to come to the store directly to make purchases. Orders made through WhatsApp also have obstacles for sellers when chats from incoming customers are excessive, so it is difficult to record incoming orders.This research was made using a waterfall system development method and developed using PHP programming language with CodeIgniter framework. System modeling in this study uses use case diagrams, activity diagrams, class diagrams and entity relationship diagrams. The result of this research is a web-based application that can be used to support and facilitate the sales transactions and purchase of ready-to-wear printed clothing and custom printed clothing.
\end{abstract}

Keyword: e-commerce, ready-to-wear apparel, printed apparel, information system 


\section{PENDAHULUAN}

Teknologi yang berkembang pesat telah mempermudah kehidupan manusia di segala bidang. Kehadiran teknologi internet dapat dimanfaatkan untuk menunjang kegiatan bisnis dalam perusahaan. Salah satu contoh pemanfaatan teknologi yang digunakan dalam melakukan proses bisnis dan perdagangan adalah e-commerce. Beberapa motif pelaku bisnis dalam menerapkan e-commerce antara lain adalah untuk mengakses pasar dalam skala global, mempromosikan produk atau jasa, membangun merek, pendekatan dengan pelanggan, membantu berkomunikasi lebih cepat dengan pelanggan, memuaskan pelanggan, menambah jumlah penjualan dan menambah jumlah pelanggan [1]. Penjualan berbasis web memunculkan berbagai peluang untuk ekspansi pasar sehingga mampu meningkatkan potensi daya saing dibandingkan bisnis perdagangan yang menjual barang secara tradisional [2].

Berkembangnya teknologi telah memungkinkan perusahaan untuk melakukan penjualan produk pakaian secara online melalui website [3]. Berkat adanya perkembangan teknologi, konsumen tidak harus mengunjungi toko untuk membeli pakaian jadi (ready-to-wear), karena kegiatan pembelian dapat dilakukan melalui website. Melalui penjualan pakaian jadi, konsumen dapat membeli pakaian dengan berbagai pilihan warna, ukuran, dan desain yang sudah tersedia. Namun, konsumen juga membutuhkan pakaian yang bisa dikustomisasi dalam hal warna, ukuran, dan juga desainnya. Munculnya bisnis pakaian sablon dapat membantu konsumen dalam memenuhi kebutuhannya. Konsumen dapat mendesain pakaiannya serta melakukan pemesanan dalam jumlah besar untuk memenuhi kebutuhannya, contohnya adalah pemesanan kaos sablon untuk keperluan event di suatu organisasi.

Toko XYZ merupakan toko yang menjual pakaian sablon ready-to-wear serta menyediakan jasa sablon pakaian custom. Penjualan pada Toko XYZ dilakukan secara offline (pembeli datang langsung ke toko) dan melalui aplikasi media sosial WhatsApp. Terdapat beberapa kekurangan dari sistem penjualan yang ada pada Toko XYZ, yaitu pemesanan yang dilakukan secara offline menjadi kurang efisien karena customer harus berkunjung ke toko secara langsung ketika ingin melakukan pembelian. Pemesanan yang dilakukan melalui aplikasi media sosial WhatApp juga memiliki kekurangan bagi Toko XYZ, yaitu ketika chat dari customer yang masuk terlalu banyak sehingga sulit untuk melakukan pencatatan banyaknya pesanan yang masuk. Dari kendala-kendala tersebut, peran $e$ - commerce dibutuhkan untuk membantu toko pakaian sablon membuat proses penjualan dan pembelian menjadi lebih efisien.

Konsep Mass Customization telah menjadi strategi baru, baik untuk pengusaha bisnis pakaian dan konsumen di era modern ini, karena dapat melayani kebutuhan customer dengan lebih spesifik [4]. Mass Customization memungkinkan konsumen untuk berpartisipasi dalam proses desain untuk membantu memastikan kualitas dan kuantitas produk memenuhi kebutuhan mereka. Berdasarkan konsep tersebut, maka pihak pengusaha pakaian sablon dapat mengerti kebutuhan dari masing-masing konsumennya dengan lebih baik.

Sistem aplikasi berbasis web pada penelitian ini dirancang menggunakan PHP dan MySQL. Tujuan penelitian ini adalah untuk membuat website toko pakaian sablon yang memungkinkan konsumen untuk melakukan pembelian pakaian sablon.

Berikut merupakan beberapa penelitian yang pernah dilakukan sebagai bahan perbandingan dan kajian:

1) Pada [3], perusahaan akan berusaha melakukan yang terbaik untuk menyediakan pelayanan bagi para pelanggan dengan membangun sistem yang memudahkan pelanggan untuk berbelanja pakaian dengan akses yang mudah, dimanapun dan kapanpun tanpa harus mengunjungi toko.

2) Sebagaimana disebutkan pada [16], indikatorindikator yang ada pada situs web perbelanjaan fashion (attractiveness, layout and structures, proper use of fonts, colors and multimedia, finding information, dan ease of use) secara signifikan berpengaruh pada kepuasan customer yang menggunakan situs web e-commerce.

3) Pada [4], dalam pendekatan mass customization pada pemasaran e-commerce, situs web harus dapat menawarkan produk yang beragam dan menanggapi kebutuhan setiap pelanggan. Elemen desain web pun memainkan peranan besar dalam membantu pelanggan merancang jenis pakaian dan detailnya sesuai yang mereka inginkan.

4) Sistem informasi penjualan berbasis web secara signifikan dapat meningkatkan pangsa pasar dengan proses bisnis yang lebih dinamis dan interaktif serta mempunyai diferensiasi yang jelas untuk seluruh segmen masyarakat [2].

5) Pada [15] terdapat sejumlah masalah yang belum terselesaikan terkait dengan e-commerce yang berorientasi konsumen pada umumnya, khususnya pada industri pakaian. Agar industri pakaian mampu bertahan di era e-business, perlu adanya lanjutan penelitian dan pengembangan pada model 
virtual dan presentasi produk pakaian di $e$ commerce.

\section{LANDASAN TEORI}

Berikut adalah merupakan beberapa landasan teori dari penelitian ini.

\subsection{Sablon}

Sablon berasal dari Bahasa Belanda yaitu schablon [5]. Dalam Bahasa Belanda, kata schablon berarti template. Sablon merupakan teknik untuk mencetak tinta di atas bahan dengan bentuk yang dikehendaki [6]. Sablon dapat diartikan sebagai pencetakan desain pola ke dalam suatu media yang dibuat berdasarkan template atau model yang telah dibuat sebelumnya.

\subsection{Teknik Sablon Digital}

Sablon digital telah menjadi trend bisnis kreatif dalam industri percetakan dan juga pakaian. Sablon digital dikenal juga dengan digital printing. Sablon digital merupakan kegiatan cetak mencetak gambar yang menggunakan mesin-mesin canggih berupa printer [7].

\subsection{Pakaian}

Pakaian merupakan salah satu bagian dari kebutuhan pokok manusia. Makna dari pakaian adalah benda yang dapat dipakai dan dikenakan pada tubuh seperti kemeja, baju dan celana. Pakaian dapat digunakan untuk mendefinisikan dan mengkomunikasikan identitas sosial pemakainya kepada orang lain [8]. Ada beberapa faktor yang mempengaruhi orang-orang dalam membeli pakaian mereka, antara lain keunikan dan konsep, brand, word of mouth, dan kualitas yang dirasakan [9].

\subsection{Mass Customization}

Mass Customization adalah kemampuan dalam menyediakan produk atau jasa yang disesuaikan melalui proses fleksibel dalam volume tinggi dan dengan biaya yang cukup rendah [10]. Terdapat empat strategi Mass Customization utama [11], yaitu; Collaborative, Transparent, Adaptive dan Cosmetic Mass Customization.

\subsection{E-commerce}

Menurut Kalakota dan Whinston, terdapat tiga definisi mengenai $e$-commerce [12]:
1) Dari sudut pandang komunikasi, e-commerce adalah proses untuk menyediakan barang, jasa, informasi atau pembayaran dengan dukungan jaringan komputer maupun perangkat elektronik lainnya.

2) Dari sudut pandang proses bisnis, e-commerce adalah adalah aplikasi teknologi yang dibuat untuk melakukan otomasi transaksi bisnis serta langkah-langkahnya (workflow).

3) Dari sudut pandang layanan, e-commerce adalah instumen yang mampu memenuhi keinginan perusahaan, manajemen, dan konsumen untuk mengurangi biaya layanan dalam usaha meningkatkan kualitas barang serta kecepatan layanan pengiriman.

\subsection{System Development Life Cycle}

System Development Life Cycle (SDLC) adalah rangkaian proses yang berfungsi untuk mengetahui bagaimana sistem informasi dapat memberikan dukungan pada kebutuhan bisnis dengan melakukan rancang bangun sebuah sistem serta menyampaikannya kepada user. SDLC memiliki empat tahapan dasar yaitu tahap perencanaan, analisis, perancangan dan implementasi. Setiap tahapan yang ada memiliki serangkaian langkah dalam pengembangannya yang mana menghasilkan deliverable atau produk dari proses pengembangannya.

Tahap planning merupakan proses untuk mengerti tujuan dibuatnya sebuah sistem dan menentukan bagaimana sistem akan dibangun. Tahap analysis menentukan pihak mana yang menggunakan sistem, hal yang dilakukan oleh sistem, dan penggunaan sistem. Pada tahap design, arsitektur teknis serta desain model akan dibuat. akan dikembangkan strategi perancangan, basic architecture, spesifikasi database, dan perancangan program, yang mana akan menghasilkan spesifikasi sistem yang akan digunakan dalam pemrograman sistem. Pada tahap implementation, dilakukan support plan untuk membahas sistem yang telah dibangun dan melalui proses pengujian untuk mengidentifikasi apa yang perlu diubah pada sistem [13].

\section{PERANCANGAN SISTEM}

Dalam perancangan sistem, metodologi yang digunakan adalah studi pustaka, wawancara, dan survei. Metode studi pustaka dilakukan untuk menemukan berbagai teori yang mendasari perancangan sistem ini. Studi pustaka yang dilakukan 
bersumber dari makalah yang diterbitkan prosiding atau jurnal penelitian yang telah ada.

Metode wawancara dilakukan untuk melihat apa saja hal-hal mempengaruhi kebutuhan konsumen untuk membeli pakaian sablon. Wawancara dilakukan dengan seorang pengusaha pakaian sablon yang telah berpengalaman dalam melayani konsumen.

Metode survei dilakukan untuk mengetahui bagaimana tingkat kebutuhan serta kepuasan konsumen dalam menggunakan situs web untuk berbelanja pakaian sablon. Survei dilakukan oleh responden melalui Google Form. Survei dilakukan untuk mengumpulkan data mengenai apa yang dibutuhkan konsumen dalam situs web toko sablon pakaian.

Metode pengembangan yang digunakan dalam perancangan sistem ini adalah metode waterfall. Terdapat 5 tahapan pada model waterfall, yaitu; Pendefinisian dan Analisis Requirements, Perancangan Software, Implementasi dan Pengujian Unit, Integrasi dan pengujian sistem dan Operation and Maintenance [14].

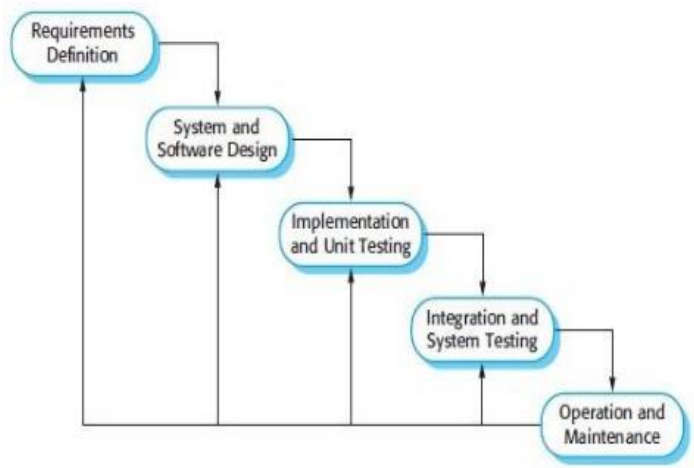

Gambar 1 Proses Model Waterfall

Secara terperinci tahapan pada model waterfall dapat dijelaskan sebagai berikut:

1) Pendefinisian dan Analisis Requirements: adalah tahap penetapan fitur, analisis masalah serta tujuan sistem melalui diskusi dan interaksi dengan user. Tahapan-tahapan tersebut berfungsi untuk spesifikasi sistem.

2) Perancangan Software: merupakan tahap pembangunan system architecture menurut persyaratan yang telah ditetapkan di tahap sebelumnya. Tahap ini dimaksudkan untuk mengidentifikasi dan menggambarkan abstraksi software system yang dibuat serta hubunganhubungannya.

3) Implementasi dan Pengujian Unit: adalah tahap yang menunjukkan realisasi perancangan software dalam suatu program. Setiap unit akan diuji apakah sudah memenuhi spesifikasinya.
4) Integrasi dan pengujian sistem: adalah tahapan integrasi setiap unit program, dan melalui tahap uji sebagai satu sistem yang utuh demi memastikan bahwa sistem yang dibuat telah dapat memenuhi persyaratan-persyaratan yang ada.

5) Operation and Maintenance: adalah tahap instalasi dan penerapan sistem. Pada tahap ini akan dilakukan pengujian saat sistem diimplementasikan agar apabila ada error dapat ditemukan selanjutnya dilakukan perbaikan.

Berikut adalah pemodelan sistem pada penelitian ini (use case, activity diagram, class dan entity relationship diagram).

\subsection{Used Case Diagram}

Use case diagram aplikasi berbasis web untuk pemesanan jasa sablon pakaian diperlihatkan pada gambar berikut.

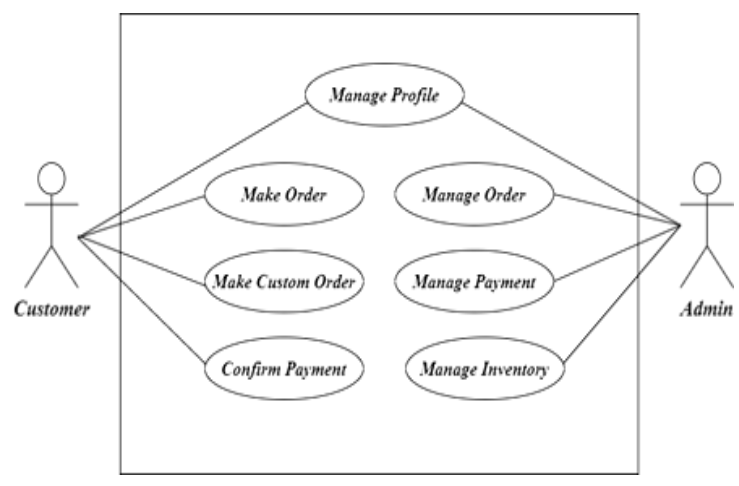

Gambar 2 Use Case Diagram Sistem

Gambar 2 merupakan use case diagram sistem usulan. Terdapat tujuh use case yang menjadi fungsi utama dalam sistem, dan dua aktor yang ada pada use case diagram ini yaitu customer dan admin.

Berikut adalah kebutuhan fungsional yang ada pada sistem pemesanan pakaian sablon untuk peran customer:

1) Mengelola akun:

a) Customer dimungkinkan untuk melakukan edit data diri

b) Customer dapat mengubah kata sandi atau password

2) Membuat pesanan (pakaian sablon non-custom):

a) Customer dapat memilih jenis pakaian, desain, jumlah, dan ukuran untuk pemesanan pakaian sablon ready-to-wear

3) Membuat pesanan (pakaian sablon custom):

a) Customer dapat melakukan pengunggahan gambar untuk desain pakaiannya 
b) Customer dapat memilih jenis pakaian, warna, jumlah, dan ukuran untuk pemesanan pakaian sablon custom

4) Melakukan konfirmasi pembayaran:

a) Customer dapat mengisi form untuk melakukan konfirmasi pembayaran

b) Customer dapat melakukan pengunggahan gambar bukti transfer untuk melakukan konfirmasi pembayaran

Berikut adalah kebutuhan fungsional yang ada pada sistem pemesanan pakaian sablon untuk peran admin:

1) Mengelola akun:

a) Admin dapat melakukan edit data diri

b) Admin dapat mengubah kata sandi atau password

2) Mengatur pesanan dari customer:

a) Admin dapat melihat detail pesanan yang datang dari customer

b) Admin dapat mengunduh hasil desain customer, dan menyerahkannya ke bagian penyablonan

c) Admin dimungkinkan untuk status pemesanan customer

3) Melakukan pengelolaan pembayaran:

a) Admin dapat data melihat detail konfirmasi pembayaran yang datang dari customer

b) Admin dapat memasukkan konfirmasi pembayaran dari customer ke dalam list success confirmation dan failed confirmation

4) Mengelola inventory:

a) Untuk jenis pakaian sablon custom, admin dapat mengubah harga dan stock pada produk

b) Untuk jenis pakaian sablon non-custom atau ready-to-wear, admin dapat mengubah nama produk, deskripsi, harga dan stock pada produk

c) Untuk jenis pakaian sablon non-custom atau ready-to-wear, admin dapat menambahkan produk baru pada inventory

\subsection{Activity Diagram}

Berikut adalah gambar activity diagram dari penelitian ini.

\subsubsection{Activity Diagram Manage Profile}

Activity diagram untuk fungsi manage profile diperlihatkan pada gambar di bawah ini:

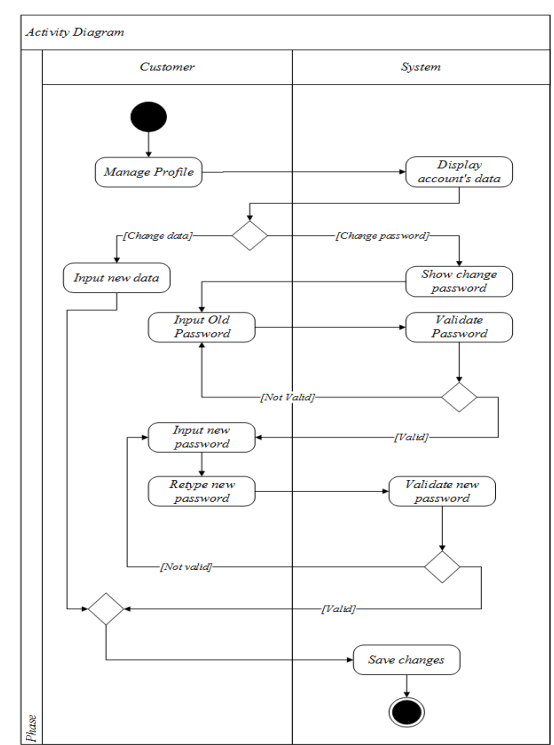

Gambar 3 Activity Diagram Manage Profile

Gambar 3 adalah activity diagram untuk mengelola profile customer dan admin.

\subsubsection{Activity Diagram Make Order}

Berikut adalah gambar activity diagram untuk fungsi make order.

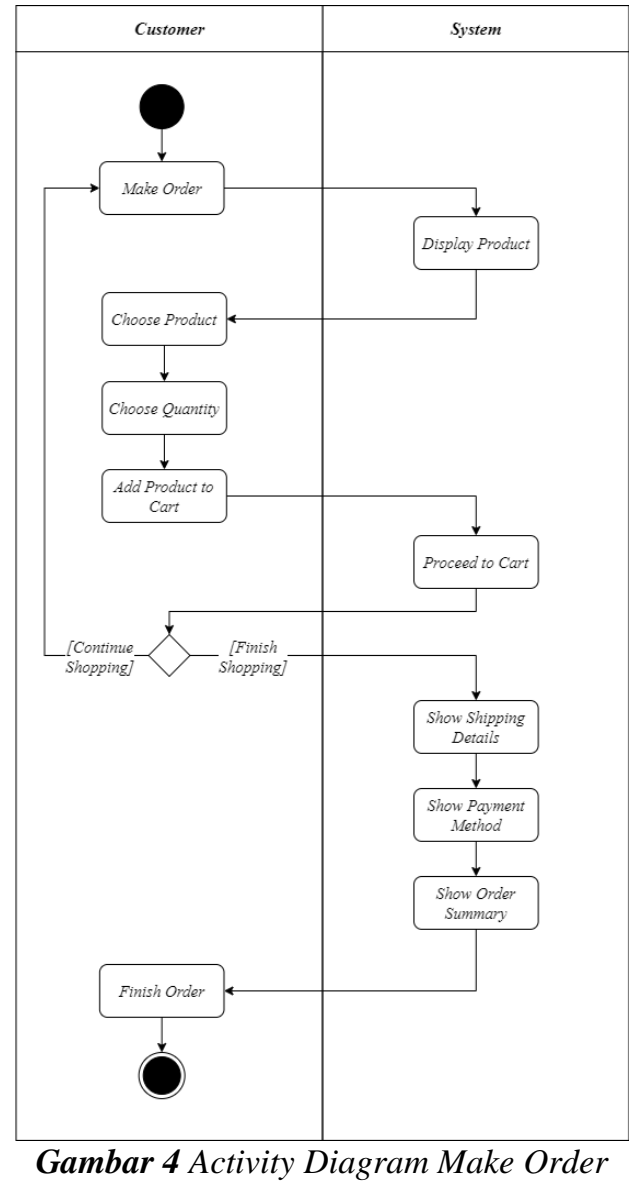


Gambar 4 adalah activity diagram dari aktivitas pemesanan pakaian non-custom atau ready-to-wear yang dilakukan customer.

\subsubsection{Activity Diagram Make Custom Order}

Activity diagram fungsi make custom order dapat diperlihatkan pada gambar berikut.

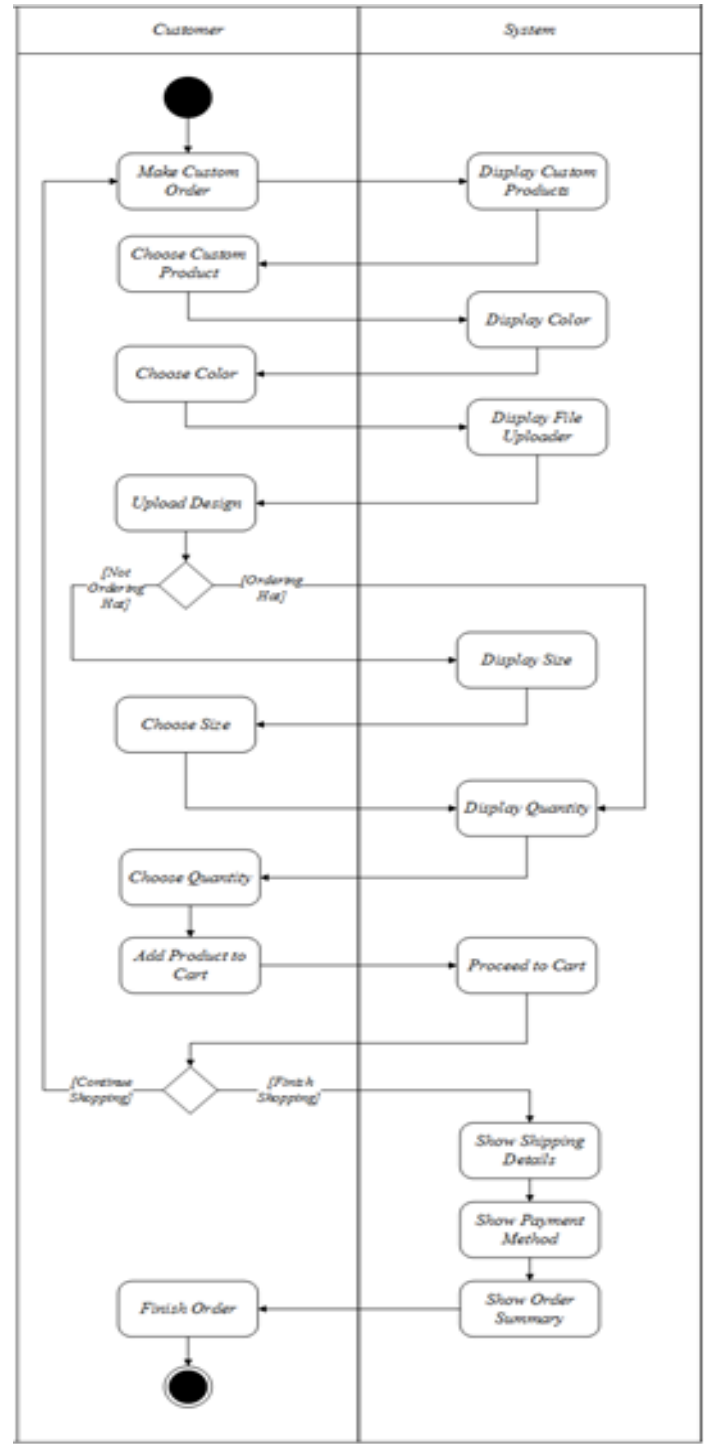

Gambar 5 Activity Diagram Make Custom Order

Gambar 5 memerlihatkan activity diagram dari aktivitas pemesanan pakaian sablon custom yang dilakukan customer.

\subsubsection{Activity Diagram Manage Order}

Activity diagram fungsi manage order dapat diperlihatkan pada gambar di bawah ini.

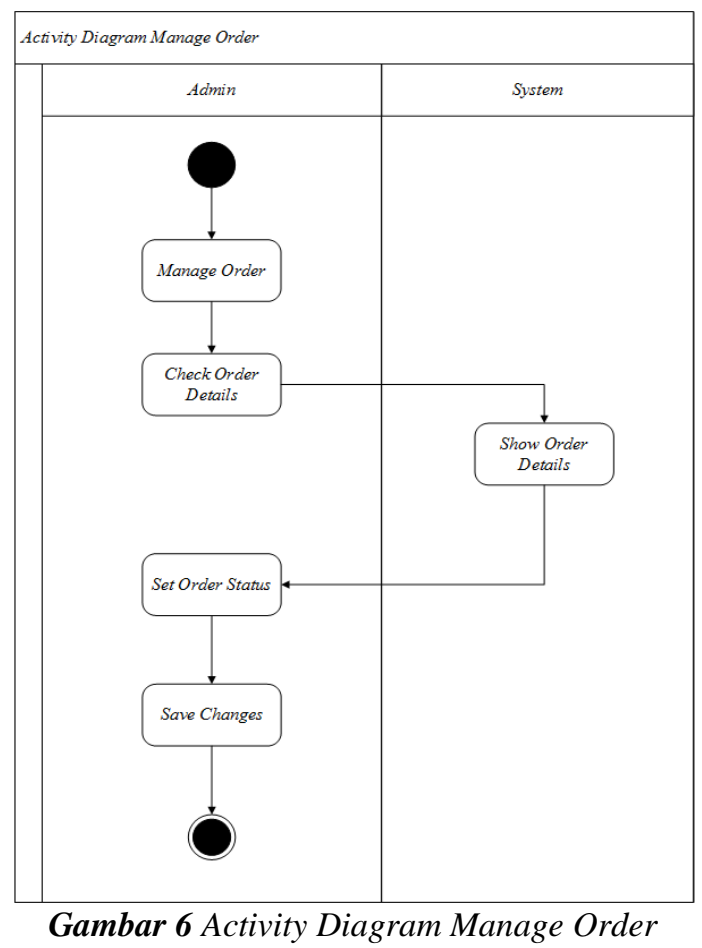

Gambar 6 menunjukkan activity diagram dari aktivitas mengolah dan mengatur pesanan customer yang dilakukan admin.

\subsubsection{Activity Diagram Manage Payment}

Activity diagram untuk fungsi manage payment dapat disajikan pada gambar berikut.

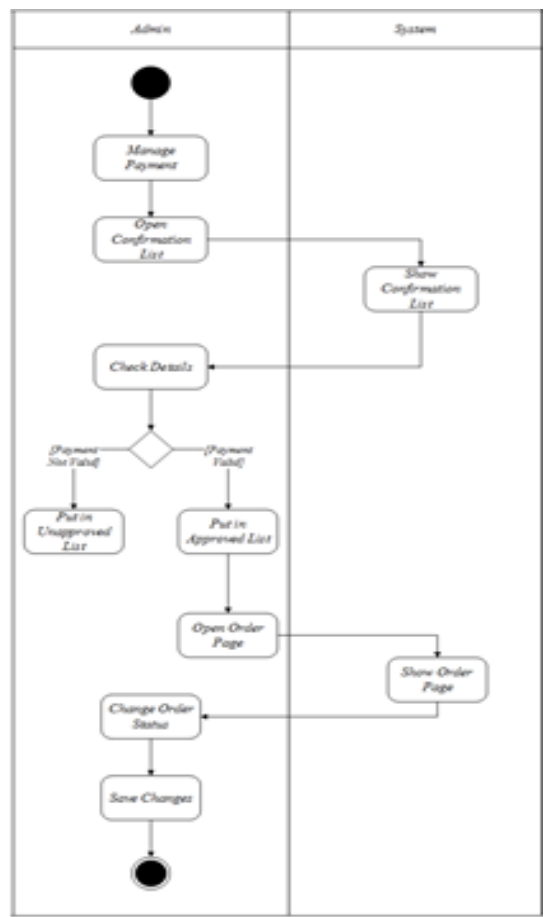

Gambar 7 Activity Diagram Manage Payment 
Gambar 7 menyajikan activity diagram dari aktivitas mengolah dan mengatur pembayaran yang dilakukan oleh admin.

\subsubsection{Activity Diagram Manage Inventory}

Berikut adalah activity diagram fungsi manage inventory.

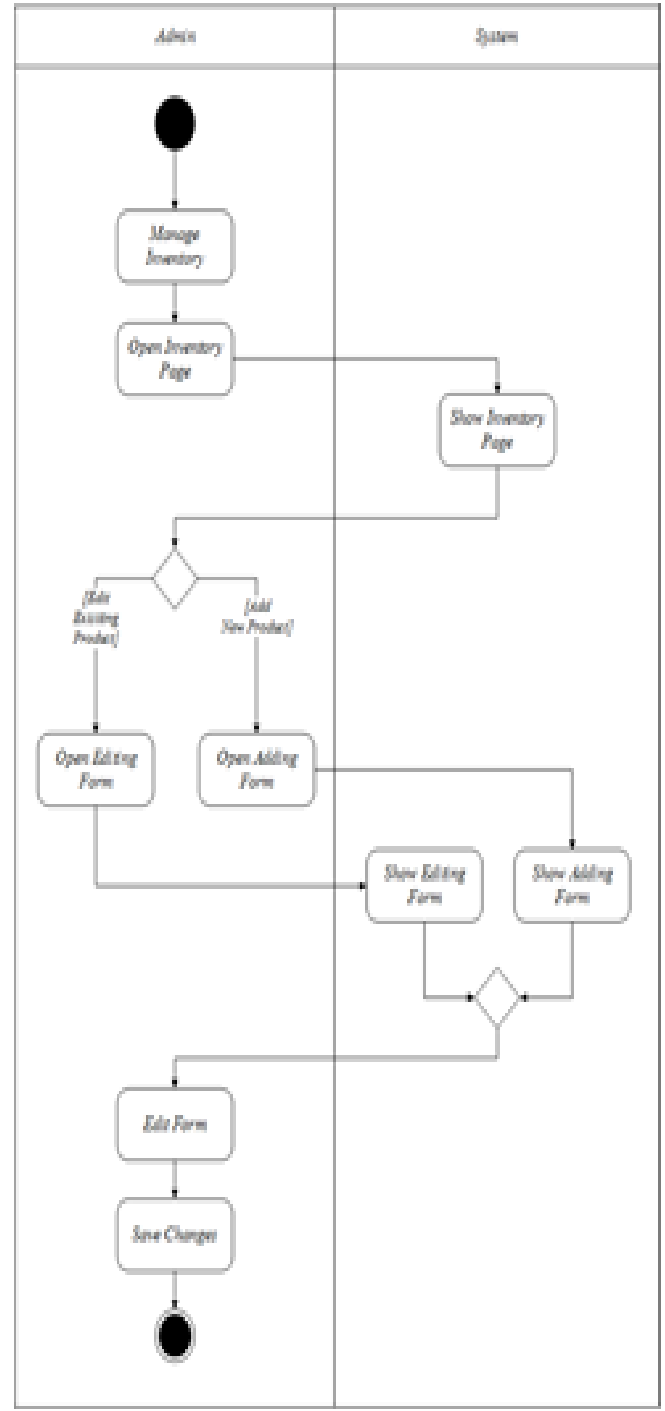

Gambar 8 Activity Diagram Manage Inventory

Gambar 8 merupakan activity diagram dari aktivitas mengolah dan mengatur inventory produk yang dilakukan admin.

\subsection{Entity Relationship Diagram}

Entity relationship diagram penelitian ini dapat diperlihatkan pada gambar berikut.

Copyright $\left({ }_{0} 2020\right.$ FT-UHAMKA. - All rights reserved DOI: 10.22236/teknoka.v5i.338

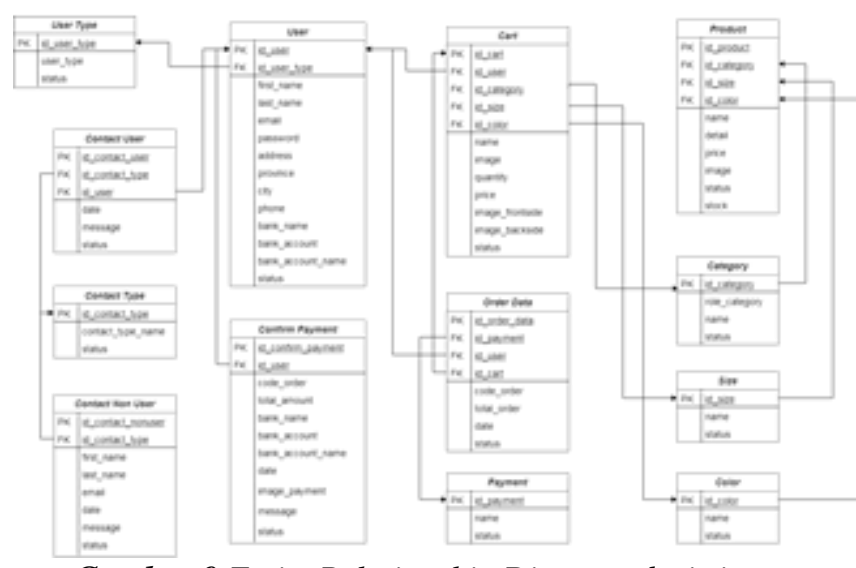

Gambar 9 Entity Relationship Diagram dari sistem

Gambar 9 merupakan diagram yang menunjukan relasi yang terjalin antara tabel-tabel data.

\section{IMPLEMENTASI DAN PENGUJIAN}

Berikut merupakan implementasi dan pengujian dari sistem ini.

\subsection{Implementasi}

Implementasi sistem dilakukan menggunakan bahasa pemrograman PHP dengan framework CodeIgniter dan MySQL. Berikut adalah tampilan halaman landing page, customer, dan admin.

\subsubsection{Perancangan Antarmuka untuk Landing Page}

Berikut adalah beberapa gambar dari tampilan antarmuka untuk halaman landing page pada perancangan sistem ini.

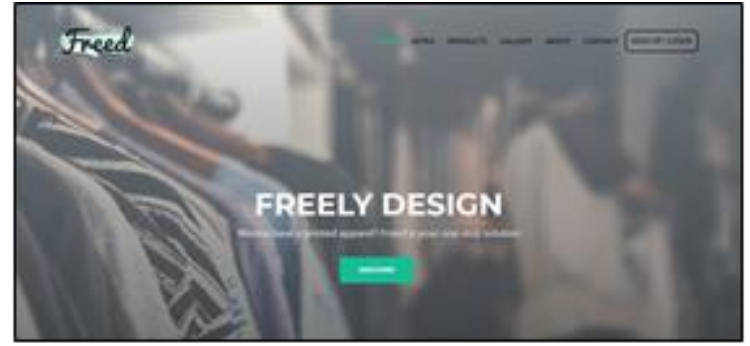

Gambar 10 Tampilan Home pada Landing Page

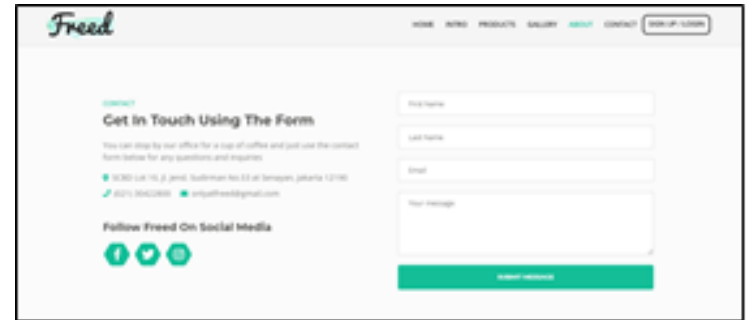

Gambar 11 Tampilan Contact pada Landing Page Seminar Nasional TEKNOKA ke - 5, Vol. 5, 2020 ISSN No. 2502-8782 


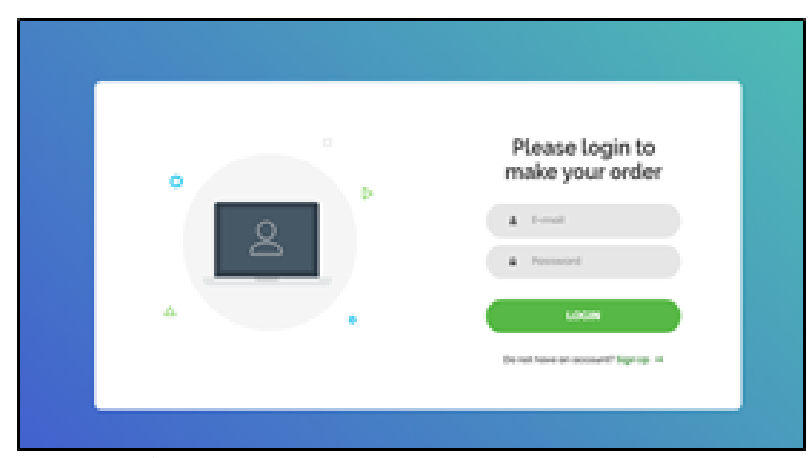

Gambar 12 Tampilan Login pada Landing Page

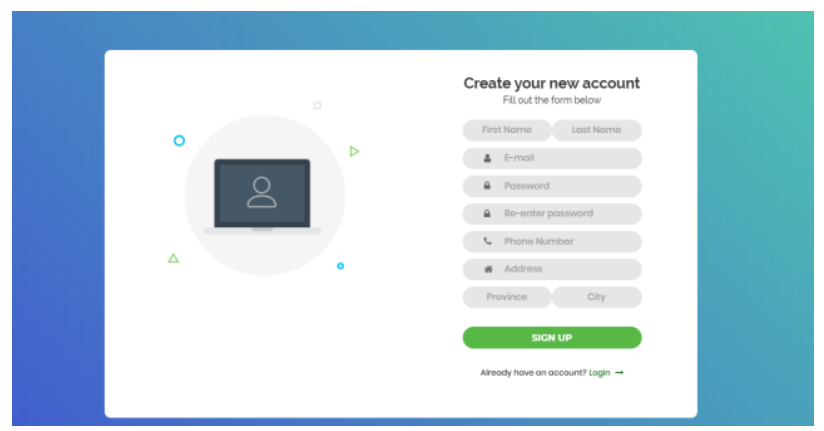

Gambar 13 Tampilan Sign Up pada Landing Page

Gambar 10 merupakan tampilan dari halaman landing page saat pertama kali diakses. Gambar 11 adalah kolom contact, yaitu form yang dapat diisi untuk menyampaikan pesan kepada pihak toko. Gambar 12 merupakan halaman login yang dapat diakses dari landing page. Pengguna dapat memasukkan email dan password agar dapat melakukan login untuk masuk ke dalam sistem. Gambar 13 merupakan tampilan dari halaman sign up, dimana pengguna dapat membuat akun baru dengan mengisi form yang tersedia.

\subsubsection{Perancangan Antarmuka untuk Customer}

Berikut adalah beberapa gambar dari tampilan antarmuka untuk halaman customer pada perancangan sistem ini.

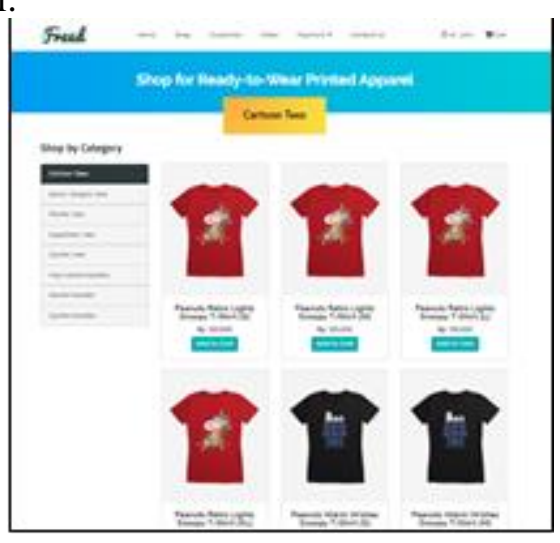

Copyright $(02020$ FT-UHAMKA. - All rights reserved DOI: 10.22236/teknoka.v5i.338
Gambar 14 Tampilan Halaman Pembelian Pakaian Sablon Non-Custom

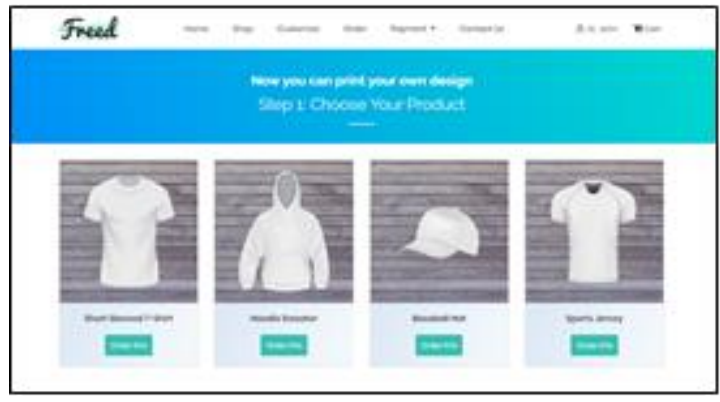

Gambar 15 Tampilan Halaman Pembelian Pakaian Sablon Custom

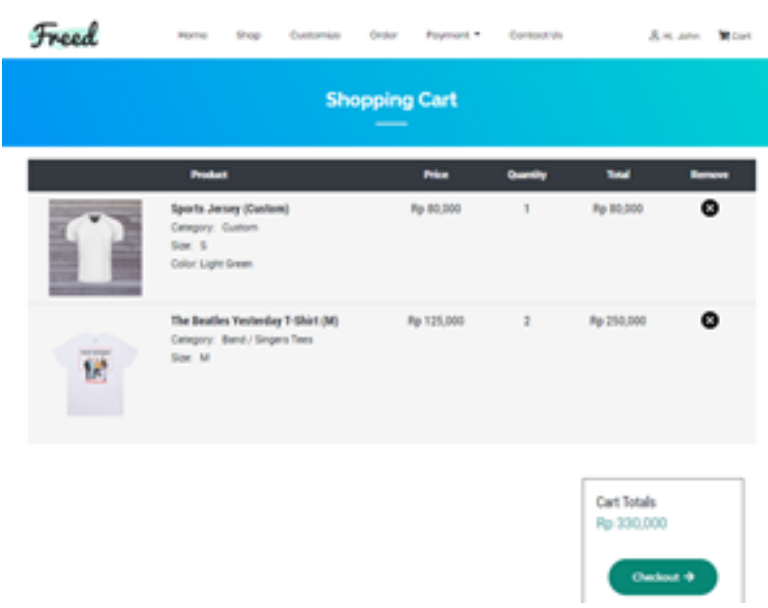

Gambar 16 Tampilan Halaman Shopping Cart

Gambar 14 merupakan tampilan dari halaman pembelian pakaian sablon non-custom, dan Gambar 15 merupakan tampilan dari halaman pembelian pakaian sablon custom. Untuk tampilan shopping cart dapat dilihat pada Gambar 16. Customer dapat melanjutkan pembelian dengan menekan tombol "checkout".

\subsubsection{Perancangan Antarmuka untuk Admin}

Berikut adalah beberapa gambar dari tampilan antarmuka untuk halaman admin pada perancangan sistem ini.

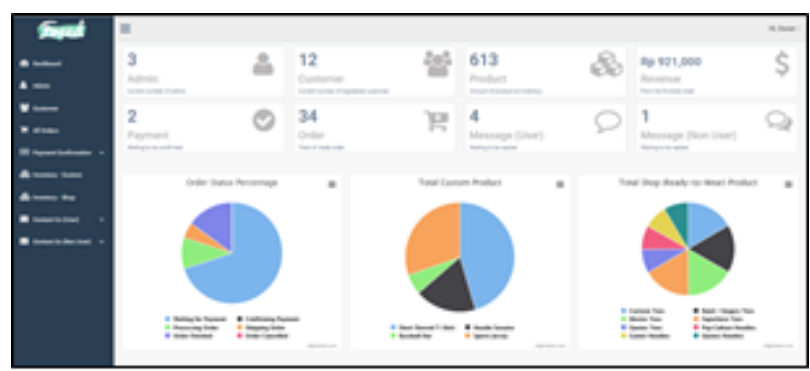

Gambar 17 Tampilan Halaman Dashboard 


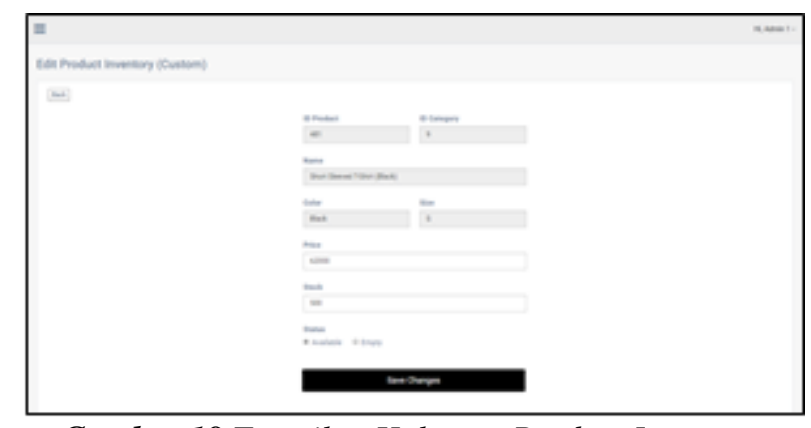

Gambar 18 Tampilan Halaman Product Inventory

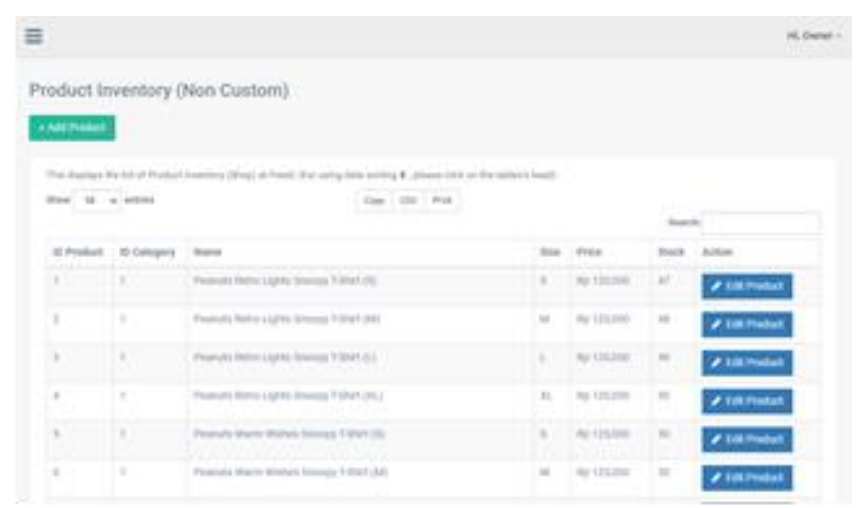

Gambar 19 Tampilan Halaman Edit Inventory

Gambar 17 merupakan tampilan dari halaman dashboard, dimana admin dapat melihat beberapa informasi mengenai pembelian dan penjualan. Gambar 18 merupakan tampilan dari halaman product inventory. Pada halaman ini, produk-produk yang dijual dapat dilihat secara detail (nama, varian, jumlah stock, dan yang lainnya). Gambar 19 merupakan halaman edit inventory. Pada halaman ini, admin dapat melakukan perubahan data produk yang telah dipilih di halaman product inventory.

\subsection{Pengujian}

Sistem ini menggunakan black box testing untuk pengujiannya. Black box testing adalah pengujian yang dilakukan untuk menguji berjalannya suatu software, dengan mengamati hasil eksekusi dari software tersebut. Metode black box memungkinkan diperolehnya serangkaian kondisi input yang menggunakan seluruh persyaratan fungsional pada program [17].

Black box memiliki beberapa kelebihan, yaitu dapat mendeteksi kesalahan atau kecacatan pada sistem seperti error pada interface dan performance, tidak perlu melihat dan memeriksa source code secara terperinci dan pengujinya tidak perlu memiliki kemampuan dalam pemrograman. Kekurangan pengujian menggunakan black box adalah pengujian menjadi kurang detail sebab source code pada sistem tidak melalui pengujian.

\section{SIMPULAN}

Hasil dari perancangan sistem ini adalah aplikasi berbasis web yang dirancang agar proses transaksi pembelian dan penjualan pada toko pakaian sablon online dapat dilakukan dengan lebih mudah. Adapun kesimpulan yang didapatkan dari perancangan sistem ini adalah:

1) Sistem dapat membantu proses transaksi jual beli antara pembeli dan penjual tanpa adanya batasan tempat dan waktu;

2) Sistem memudahkan pembeli dalam melakukan pemesanan dengan menyimpan data dari pembeli serta barang yang dipesan, sehingga pembeli tidak perlu lagi melakukan pencatatan ketika melakukan pemesanan;

3) Sistem dapat menampilkan produk-produk pakaian sablon non-custom atau ready-to-wear beserta deskripsinya, sehingga mempermudah pembeli dalam mengenali dan memilih produk yang akan dibeli;

4) Sistem memfasilitasi pembeli dalam mengkustomisasi desain pakaian sablonnya, dengan menggunakan fitur pengunggahan design yang ada pada pemesanan pakaian sablon custom;

5) Sistem dapat menampilkan status pada produk yang telah dipesan oleh customer;

6) Sistem memfasilitasi admin dalam mengelola data pemesanan, data pribadi customer dan admin, serta pesan yang masuk dari halaman contact;

7) Sistem memfasilitasi admin dalam mengelola stock produk pakaian sablon non-custom dan pakaian sablon custom.

Untuk pengembangan sistem selanjutnya, berikut adalah saran yang dapat diusulkan:

1) Menambahkan plugin design studio pada website, agar pengguna dapat mendesain pakaian custom secara langsung dari website;

2) Menggunakan fitur perhitungan biaya pengiriman (shipping fee), yang mana biaya pengirimannya ditentukan oleh lokasi pengiriman dan berat produk;

3) Memberikan fitur input discount code untuk potongan harga pada halaman checkout;

4) Menambahkan metode pembayaran digital seperti melalui GoPay, OVO, DANA, dan yang lainnya.

\section{KEPUSTAKAAN}

[1] E.S.Soegoto, "The Effect of EntrepreneurshipBased Curriculum on Higher Education 
Institution Towards Non-Economic Student Entrepreneurial Interest", econosains, vol. 16, no. 1, pp. 9 - 22, Apr, 2018.

[2] Kosasi, Sandy, "Pembuatan Sistem Informasi Penjualan Berbasis Web Untuk Memperluas Pangsa Pasar," Seminar Nasional Teknologi dan Informatika (SNATIF), Vol. 1, Universitas Muria Kudus, pp. 225-232, 2014.

[3] D. S. Soegoto dan C. Cica, "Design of Webbased Sales Information System on Fashion Shop in Bandung, Indonesia," IOP Conference Series: Materials Science and Engineering, vol. 407, p. 012023, 2018.

[4] S. Tangchaiburana dan K. W. Techametheekul, "Development model of web design element for clothing e-commerce based on the concept of mass customization," Kasetsart Journal of Social Sciences, vol. 38, no. 3, pp. 242-250, 2017.

[5] G. Nusantara, "Panduan praktis cetak sablon". Jakarta: Kawan Pustaka, 2007.

[6] Sahid, Nur, "Sistem Informasi Pemesanan Jasa Sablon Clove Order Information System Screen Printing Service Clove", 2009.

[7] Shintia, Dienna, "Eksplorasi Teknik Sablon Pada Produk Ready to Wear dengan Inspirasi Lukisan Jackson Pollock", 2017.

[8] W. Moody, P. Kinderman, P. Sinha, and K.-S. You, "Identifying the Causal Relationships of Appearance Management through an Analysis of Ones Own Clothing and Wearing Experiences over a 10-day Period," Journal of the Korean Society of Clothing and Textiles, vol. 33 , no. 6 , pp. 841-852, 2009.

[9] T. H. Cham, C. K. Y. Ng, Y. M. Lim, and B. L. Cheng, "Factors influencing clothing interest and purchase intention: a study of Generation $Y$ consumers in Malaysia," The International Review of Retail, Distribution and Consumer Research, vol. 28, no. 2, pp. 174-189, 2017.
[10] Laudon, Kenneth dan Laudon Jane, "Management Information System". Pearson Education, United States, 2010.

[11] Wakoya, Abdeta \& Takele, Yitbarek, "The Effect of Mass Customization on Competitive Strategy". Journal of Management Policies and Practices, 2015.

[12] M. V. D. Velden and C. Mörtberg, "Participatory DesignDesign participatory and Design for Values," Handbook of Ethics, Values, and Technological Design, pp. 41-66, 2015.

[13] A. Dennis, B.H. Wixom and D. Tegarden, "System Analysis \& Design: An Object-Oriented Approach with UML," 5 ed., Wiley, 2015.

[14] Sommerville, Ian, "Software Engineering". 9th Edition. America: Pearson Education, Inc, 2011.

[15] Tuunainen, Virpi \& Rossi, Matti, "Ebusiness In Apparel Retailing Industry Critical Issues". 1596-1606, 2002.

[16] Wail, D \& Sfenrianto, Sfenrianto, "Analysis of customer satisfaction level on $e$ commerce web fashion product". Journal of Theoretical and Applied Information Technology. 96. 4439-4447, 2018.

[17] Sulistyanto H, Azhari Sn, "Urgensi Pengujian pada Kemajemukan Perangkat Lunak dalam Multi Perspektif', KomuniTi, Vol. VI, No. 1, Publikasi Ilmiah UMS, 2014. 